\title{
Administração pública e gestão social: a produção científica brasileira entre 2000 e 2005*
}

\author{
Antônio João Hocayen-da-Silva** \\ Luciano Rossoni*** \\ Israel Ferreira Júnior****
}

Sumário: 1. Introdução; 2. Produção científica em administração; 3. Procedimentos metodológicos; 4. Descrição e análise de dados; 5. Considerações finais.

Summary: 1. Introduction; 2. Scientific production in administration; 3. Methodological procedures; 4. Data description and analysis; 5. Final remarks.

Palavras-chave: administração pública; gestão social; metodologia de pesquisa; pesquisa acadêmica; produção científica.

KEY WORDs: public sector management; social management; research methodology; academic research; scientific production.

Nos últimos anos, observa-se grande esforço dos pesquisadores em fazer um balanço crítico das publicações científicas em diversas disciplinas. Porém, algumas áreas foram pouco contempladas, como a administração pública e gestão social. Buscando preencher essa lacuna, este artigo apresenta um quadro geral da produção científica em administração pública e gestão social com base nos dados levantados em 549 artigos publicados nos anais do Enanpad, entre os anos de 2000 e 2005. As variáveis analisadas em cada artigo foram: número de autores por artigo; instituição e estado

\footnotetext{
* Artigo recebido em set. 2006 e aceito em nov. 2007.

** Mestrando em administração pelo Centro de Pesquisa e Pós-Graduação da Universidade Federal do Paraná - Ceppad/UFPR. Endereço: Rua Engenheiro Ostoja Roguski, 631/21, bloco 3 — Jardim Botânico — CEP 80210-390, Curitiba, PR, Brasil. E-mail: hocayen@yahoo.com.br.

**** Mestrando em administração pelo Centro de Pesquisa e Pós-Graduação da Universidade Federal do Paraná - Ceppad/UFPR. Endereço: Rua Osmário de Lima, 598 - Capão da Imbuia —CEP 82810-260, Curitiba, PR, Brasil. E-mail: 1rossoni@gmail.com.

***** Mestrando em administração pelo Centro de Pesquisa e Pós-Graduação da Universidade Federal do Paraná - Ceppad/UFPR. Endereço: Rua Engenheiro Ostoja Roguski, 631/21, bloco 3 — Jardim Botânico — CEP 80210-390, Curitiba, PR, Brasil. E-mail: isjunior99@yahoo.com.br.
} 
de origem dos autores; proporção de trabalhos teóricos e empíricos; e método e estratégia de pesquisa. Verificou-se que a média de autores por artigo vem crescendo. A maioria enquadrou-se como teórico-empírico (76,1\%). Dos artigos teórico-empíricos, aproximadamente $67 \%$ utilizaram o método qualitativo, com predomínio do estudo de caso $(55,7 \%)$ como estratégia de pesquisa; porém o uso do método quantitativo vem aumentando. Entre as instituições de origem dos autores, cinco se destacaram como as mais prolíficas, respondendo por aproximadamente $50 \%$ dos artigos publicados no período; e cerca de $56 \%$ dos artigos concentraram-se em três estados do país. Public sector management and social management: Brazilian scientific
production between 2000 and 2005

Over the past few years, there has been a great effort from researchers to compile a critical assessment of scientific publications from several fields of knowledge. However, public sector management and social management have not been covered as much as other fields. In order to fill the gap, this article presents a framework of the scientific production in public management and social management based on data gathered from 549 papers published in the Enanpad proceedings between 2000 and 2005. The variables analyzed in each paper were: the number of authors per paper; the institution and state of origin of the authors; the ratio of theoretical and empirical papers; the method and research strategy used. It was found that the average number of authors per paper is growing. Most of these papers were categorized as 'theoretical-empirical'. Within the theoretical-empirical papers, approximately $67 \%$ were of qualitative nature, predominantly case studies $(55,7 \%)$ as the main research method, although it can be suggested there is a growth of quantitative methods. Among the authors' institutions or origin, five can be highlighted as the most productive, responsible for approximately $50 \%$ of the papers published within that time-frame, and around $56 \%$ of the papers can be narrowed down to three states in the country.

\section{Introdução}

Em virtude do aumento no volume de publicações científicas nas áreas do conhecimento ligadas à administração, observa-se, nos últimos anos, um grande esforço dos pesquisadores em elaborar um balanço crítico das publicações científicas em diferentes disciplinas, com o interesse de avaliar a qualidade dos trabalhos que são produzidos no Brasil. Normalmente esses estudos caracterizam-se por buscar a classificação dos procedimentos metodológicos, do referencial teórico, do número de autores por artigo, do número de artigos por unidade federativa, do número de artigos por instituições de ensino e da base epistemológica. Trabalhos dessa natureza visam levantar algumas conclusões 
em relação a determinados campos do conhecimento ou disciplinas, e, dessa forma, são intitulados metaestudos.

Contudo muitas áreas ainda não foram contempladas e outras foram abordadas de forma superficial, como é o caso da área de administração pública e gestão social. Assim, buscou-se, por meio deste artigo, apresentar um quadro geral da produção científica na área, com base em dados levantados a partir dos artigos publicados nos anais do Enanpad - Encontro Nacional da Associação Nacional de Pós-Graduação e Pesquisa em Administração, levando-se em consideração o período de 2000 a 2005. Para tanto, nos artigos selecionados, foram investigadas as seguintes categorias analíticas: número de autores por artigo; idioma do artigo; nacionalidade dos autores; instituição de origem dos autores; estado de origem dos autores; tipo de pesquisa; método de pesquisa; e estratégia de pesquisa.

O estudo justifica-se em função do reduzido número de pesquisas empíricas que foram encontradas (Fleury et al., 2003; Keinert, 2000; Pacheco, 2003), com o interesse de avaliar as situações qualitativa e quantitativa da produção científica na área de administração pública e gestão social no meio acadêmico/científico brasileiro. $\mathrm{O}$ artigo contribui ainda para a apresentação dos caminhos que são percorridos pelos pesquisadores, bem como as tendências que poderão ser adotadas em futuras pesquisas da área.

O artigo está organizado em cinco seções. Após introdução, são apresentados trabalhos que analisaram a produção científica em diferentes disciplinas da área de administração. Posteriormente, são discutidos os procedimentos metodológicos. Por fim, temos os resultados e as considerações finais, com as propostas para futuras pesquisas.

\section{Produção científica em administração}

Os metaestudos intensificaram-se em anos recentes, com alguns focando o campo da administração de forma ampla (Bertero, Caldas e Wood Jr., 1998 e 1999; Fleury, 2003; Wood Jr. e Paula, 2002), outros analisando disciplinas específicas como organizações (Mac-Allister, 2002; Rodrigues e Carrieri, 2001; Vergara e Pinto, 2000 e 2001), estratégia (Bertero, Vasconcelos e Binder, 2003; Bignetti e Paiva, 2001 e 2002), marketing (Froemming et al., 2000a e 2000b; Vieira, 1998, 1999, 2000 e 2003), recursos humanos (Caldas, Tonelli e Lacombe, 2002; Tonelli et al., 2003), sistema de informação (Hoppen e Meirelles, 2005), contabilidade (Cardoso, Mendonça Neto e Sakata, 2005), finanças (Camargos, Coutinho e Amaral, 2005; Leal, Oliveira e Soluri, 2003) 
e administração da ciência e tecnologia (Rossoni, Ferreira Júnior e Hocayenda-Silva, 2006).

A avaliação da produção científica brasileira teve início com o trabalho desenvolvido por Machado-da-Silva, Cunha e Amboni (1990), que buscaram, por meio da análise de artigos da área de organizações publicados entre 1985 e 1989, demonstrar a necessidade de se avaliar a produção científica brasileira. Os autores concluíram que tais trabalhos apresentaram certa carência em relação ao referencial teórico adotado, com predominância de citações estrangeiras. Metodologicamente, são limitados em função do baixo rigor das estratégias de pesquisa adotadas. Para Machado-da-Silva, Cunha e Amboni (1990), esses dados chamam a atenção para o fato de que, embora a produção científica na área de organizações tenha apresentado uma evolução quantitativa, qualitativamente não demonstrou grandes avanços.

Bertero e Keinert (1994) avaliaram a evolução da produção científica brasileira na área de análise organizacional, entre os anos de 1961 e 1993. Os autores identificaram variáveis sociológicas e psicológicas como as mais comuns nos trabalhos. No entanto ressaltaram que ainda foram encontrados trabalhos com vertentes da estratégia, da ciência política e da comunicação. Bertero e Keinert (1994) concluíram que a produção científica priorizou a replicação e divulgação de idéias desenvolvidas por escolas estrangeiras, os trabalhos eram predominantemente acadêmicos, isolando-se a administração do processo de gestão organizacional, e foram trabalhos de baixo poder inovador e de restrito apoio empírico.

No ano seguinte, Vergara e Carvalho Jr. (1995) avaliaram o tipo, a origem e o padrão de citações da produção científica brasileira na área de organizações. Os autores concluíram, assim como Bertero e Keinert (1994), que houve nos trabalhos dos pesquisadores brasileiros a predominância de material bibliográfico (livros e artigos) de natureza estrangeira, demonstrando que a referência aos autores brasileiros era mínima.

Após a publicação desses três trabalhos, tornou-se uma constante no meio acadêmico o desenvolvimento de estudos com o objetivo de avaliar a produção científica brasileira em diferentes áreas do conhecimento inseridas na grande área de administração.

Seguindo essa tendência, Hoppen e co-autores (1998) avaliaram as publicações científicas brasileiras da área de sistema de informação entre os anos de 1990 e 1997. Concluíram que era grande a proporção de ensaios teóricos, com cerca de $41 \%$ dos trabalhos. Entre os trabalhos empíricos, houve a predominância das estratégias de pesquisa de estudo de caso e survey que, juntas, representaram $72 \%$ do total. No entanto os autores ressaltaram a baixa quali- 
dade dos trabalhos desenvolvidos na área, em virtude da descrição incompleta dos procedimentos metodológicos utilizados, da inexistência de validação dos instrumentos de pesquisa e da não-explicação dos procedimentos de operacionalização da base teórica adotada.

Froemming e co-autores (2000b) realizaram um inventário das características metodológicas básicas da produção científica da área de marketing na década de 1990 (até o ano de 1998). Foram levantados 217 artigos e após serem descartados 83 ensaios teóricos, o estudo foi efetuado com uma amostra de 134 trabalhos empíricos. Os autores identificaram que $41 \%$ dos artigos eram de natureza exploratória, $53 \%$ de natureza descritiva e $6 \%$ exploraram relações de causalidade. Em relação ao método de pesquisa, 76,12\% eram surveys; 20,90\% qualitativos; e 2,99\% experimentos. Apesar de 91,79\% dos artigos apresentarem a justificativa do estudo e $88,81 \%$ os procedimentos metodológicos, $67,16 \%$ não descreveram as hipóteses e os pressupostos de base, $85,07 \%$ dos artigos não apresentaram o modelo de pesquisa utilizado e $72,39 \%$ não demonstraram os métodos de operacionalização das variáveis.

Focando a área de recursos humanos, Caldas, Tonelli e Lacombe (2002) analisaram os artigos publicados no Enanpad na década de 1990, priorizando: temática, base epistemológica, procedimentos metodológicos, padrão de referência e demografia de autoria. Os autores identificaram que $76 \%$ dos artigos adotaram o paradigma funcionalista; $15 \%$ o interpretacionista; $9 \%$ o humanista radical; e apenas um artigo adotou o paradigma estruturalista radical. Quanto à abordagem, 16\% eram teóricos e $84 \%$ eram teórico-empíricos, dos quais $40 \%$ eram qualitativos; $23 \%$ eram quantitativos e $37 \%$ eram quali-quanti. Em $90 \%$ dos estudos foi realizado estudo de caso, os 10\% restantes estavam distribuídos entre biografia, fenomenologia, grounded theory e etnografia. Os autores concluíram que a pesquisa na área cresceu em quantidade, e não em qualidade, com predominância de literatura estrangeira e concentração em um conjunto limitado de autores e programas.

Bertero, Vasconcelos e Binder (2003) desenvolveram uma avaliação da produção científica em estratégia entre os anos de 1991 e 2002, analisando as seguintes categorias: critérios temáticos, metodologias adotadas, autores e vinculações institucionais dos autores. Em relação à temática, destacaram-se os fundamentos organizacionais em $18,2 \%$ dos artigos; Porter e fundamentos econômicos em 14,9\%; planejamento estratégico e processo decisório em $8,3 \%$ cada; e recursos e competências em $6,3 \%$ dos artigos. Metodologicamente, observou-se que $66,3 \%$ dos artigos eram empíricos, dos quais $43,2 \%$ eram qualitativos, $19,1 \%$ quantitativos e $4 \%$ quali-quanti. Em $28,4 \%$ dos artigos identificou-se metodologia teórica, sendo $19,8 \%$ ensaio, 5,6\% proposição 
de modelo e 3\% consistiam apenas em revisão teórica. Em 43,9\% dos artigos analisados constou apenas um autor, com dois autores são 39,6\% dos artigos e 13,2\% dos artigos com três autores. Bertero, Vasconcelos e Binder (2003) concluíram que a produção científica da área não é prática, colaborando para a inexistência de resultados que servem como medida de desempenho para o meio empresarial.

Mariz e co-autores (2004), analisando a área de teoria das organizações, apresentaram uma revisão crítica da metodologia utilizada nos trabalhos publicados no Enanpad de 1999 a 2002. Foram investigados o delineamento da pesquisa, as técnicas de coleta de dados e as dimensões e os recursos da análise de dados. Os autores identificaram que 77,78\% dos trabalhos eram qualitativos, $13,33 \%$ quantitativos e $8,89 \%$ multimétodos. Na estratégia de pesquisa sobressaiu em $31,11 \%$ dos trabalhos o estudo de caso; em $30 \%$ o estudo qualitativo básico; e em 13,33\% survey. Entre as técnicas de coleta de dados, observou-se que em 33,30\% dos artigos foram utilizadas entrevistas e fontes secundárias; em 22,20\% entrevistas e outras técnicas; e 17,80\% utilizaram somente entrevista. Mariz e co-autores (2004) concluíram que havia predominância de estudos qualitativos e uma tendência à utilização de métodos interpretativistas para a análise dos dados.

Mais recentemente, Cardoso, Mendonça Neto e Sakata (2005) analisaram as características metodológicas, a evolução e a temática das publicações científicas em contabilidade, bem como a produção de seus autores. Identificaram 75 diferentes estratégias de pesquisa, entre elas 33,3\% eram laboratório; 26,7\% observação; $14,7 \%$ empírico-descritiva; $13,3 \%$ estudo de caso; $10,7 \%$ pesquisa de campo; e 1,3\% bibliográfica. Em relação à temática abordada, observou-se que $46,6 \%$ estavam ligadas à área de contabilidade de custos e contabilidade gerencial; $16,7 \%$ abordaram contabilidade e mercados de capital; $16,6 \%$ contabilidade pública e tributária; e 6,7\% orçamento. Cardoso, Mendonça Neto e Sakata (2005) concluíram que os autores nacionais da área contábil apresentaram uma produção menor do que a produção internacional, além da concentração de publicações entre poucos autores.

Especificamente na área de administração pública e gestão social, Keinert (2000) buscou caracterizar os paradigmas da administração pública no Brasil, em função do conceito de público. Para tanto, a autora analisou os artigos publicados entre 1937 e 1997 na Revista de Administração Pública (RAP) e na Revista do Serviço Público (RSP). Os resultados principais apontaram uma substituição da discussão tecnicista/unicista/autoritária para uma discussão mais ampla do papel do Estado, além de abordar questões de democratização e gestão participativa, movimentos sociais e terceiro setor, bem como ensino 
e pesquisa em administração pública. A autora concluiu que, de acordo com a produção acadêmica em administração pública, houve ampliação de paradigma que foi do público como estatal ao público como interesse público.

Um segundo trabalho na área de administração pública e gestão social foi desenvolvido por Pacheco (2003); utilizando como base os artigos publicados entre 1995 e 2002 na $R A P$ e na $R S P$, ele buscou analisar qualitativamente a produção científica brasileira na área de pesquisa em administração pública. A autora observou que era grande a diversidade temática apresentada pelos artigos publicados na $R A P$, em que os temas principais foram organizações, reforma gerencial do Estado, implementação de políticas públicas, sociologia, política, demografia, finanças públicas, estudos setoriais e ferramentas administrativas e de gestão. Já a $R S P$, em função de sua linha editorial, apresentou maior homogeneidade entre suas publicações. Seus temas estavam mais ligados ao Estado, à administração pública e à gestão governamental. Entre os estudos analisados, houve predomínio da estratégia de pesquisa de estudo de caso, abordando basicamente setores isolados da economia. A autora apontou a tendência de pesquisadores citarem a si próprios, de diluição temática e de adoção acrítica de teorias desenvolvidas em outras disciplinas.

Em seguida, Fleury e co-autores (2003), analisando os artigos publicados na $R A P$ no período de 1992 a 2002, buscaram mapear o perfil dos autores e o perfil do conteúdo dos artigos. Quanto ao perfil dos autores, identificaram que somente $10,5 \%$ dos artigos representaram publicação conjunta entre professor e aluno; 63,7\% dos artigos foram publicados por homens; 93,2\% dos autores eram brasileiros; $55,2 \%$ dos autores eram mestres e doutores; $54 \%$ dos trabalhos foram publicados por instituições de natureza pública; e os estados do Rio de Janeiro e de São Paulo dominaram cerca de 58\% das publicações na área. Quanto ao conteúdo dos artigos, observou-se que $83 \%$ dos textos continham de cinco a 25 páginas; $62,6 \%$ dos trabalhos foram escritos por somente um autor; e o estudo de caso foi a estratégia de pesquisa utilizada em $32 \%$ dos artigos.

De forma generalizada, tais estudos chegaram a conclusões semelhantes, apesar de muitos avaliarem disciplinas distintas. Há um consenso que quantitativamente a produção na área de administração vem crescendo (Bertero, Caldas e Wood Jr., 1998 e 1999; Froemming et al., 2000b; Hoppen e Meirelles, 2005; Tonelli et al., 2003; Vergara e Pinto, 2000 e 2001). Contudo, apesar do crescimento quantitativo, a qualidade dos estudos não acompanha tal aumento (Froemming et al., 2000b; Hoppen e Meirelles, 2005; Machado-da-Silva, Cunha e Amboni, 1990; Perin et al., 2000). 
Pode-se também dizer que o trabalho de pesquisa no campo da administração é solitário, pois grande parte dos artigos possui somente um autor (Bertero, Vasconcelos e Binder, 2003; Caldas, Tinoco e Chu, 2003; Camargos, Coutinho e Amaral, 2005; Fleury et al., 2003; Vieira, 1998 e 2003), apesar da publicação conjunta vir crescendo (Bertero, Vasconcelos e Binder, 2003; Fleury et al., 2003; Vieira, 2003); com excesso de citações a referências estrangeiras e com poucas citações a autores brasileiros (Bignetti e Paiva, 2001 e 2002; Caldas, Tinoco e Chu, 2003; Camargos, Coutinho e Amaral, 2005; Rodrigues e Carrieri, 2001; Vergara e Pinto, 2000 e 2001; Vieira, 1998 e 2003); de base epistemológica predominantemente funcionalista (Caldas, Tonelli e Lacombe, 2002; Pegino, 2005; Tonelli et al., 2003); e com poucas instituições concentrando a maior parte dos estudos (Berter, Vasconcelos e Binder, 2003; Caldas, Tinoco e Chu, 2003; Camargos, Coutinho e Amaral, 2005; Fleury et al., 2003; Tonelli et al., 2003; Vergara e Pinto, 2000 e 2001; Vieira, 1998 e 2003).

Observa-se ainda, nos estudos empíricos, que há predominância de estudos qualitativos, em sua maioria utilizando a estratégia de estudo de caso (Hoppen e Meirelles, 2005; Rodrigues e Carrieri, 2001; Tonelli et al., 2003), sendo minoria somente na área de marketing (Vieira, 1998 e 2003), finanças (Leal, Oliveira e Soluri, 2003) e contabilidade (Mendonça Neto et al., 2004).

Seguindo a tendência de avaliação da produção científica nas diversas disciplinas da área de administração, buscou-se com o presente artigo avaliar os indicadores da pesquisa científica na área de administração pública e gestão social. Os procedimentos metodológicos para tal realização vêm expostos a seguir.

\section{Procedimentos metodológicos}

Este artigo pode ser classificado como descritivo, já que busca descrever processos, mecanismos e relacionamentos existentes na realidade do fenômeno estudado, utilizando-se, para tanto, um conjunto de categorias ou tipos variados de classificações (Neuman, 1997). Castro (1978:66) enfatiza que uma pesquisa de cunho descritivo "se limita a uma descrição pura e simples de cada uma das variáveis isoladamente, sem se preocupar com as interações entre elas". Caracteriza-se como um estudo quantitativo, em que os resultados são quantificados e apresentados por meio de medidas objetivas que contribuem para a confiabilidade do estudo e permitem estabelecer conclusões seguras (Godoy, 1995). 
A estratégia utilizada foi a pesquisa documental, onde foram analisados os artigos referentes à área de administração pública e gestão social do Enanpad. Moreira (2005) salienta que a pesquisa documental caracteriza-se como processo de levantamento, verificação e interpretação de documentos, tendo como objetivo um fim predeterminado que, conforme observam Marconi e Lakatos (1990), pode ser efetuada ao longo dos anos, pois as informações estarão arquivadas nos referidos documentos.

Buscando apresentar um quadro geral da produção científica em administração pública e gestão social, foram levantados os artigos publicados nos anais do Enanpad, no período de 2000 a 2005. Esse evento foi selecionado em virtude de sua classificação, "A", no sistema Qualis da Capes (Coordenação de Aperfeiçoamento de Pessoal de Nível Superior).

Foram analisados 549 artigos na área de administração pública e gestão social do Enanpad, sendo 41 em 2000 (área de administração pública); 59 em 2001 (35 na área de gestão pública e governança; e 24 na área de políticas públicas); 64 em 2002 (38 na área de gestão pública e governança; e 26 na área de políticas públicas); 112 em 2003 (42 na área de gestão social e ambiental; 32 na área de gestão pública e governança; e 38 na área de políticas públicas); 148 em 2004 (63 na área de gestão social e ambiental; 45 na área de gestão pública e governança; e 40 na área de políticas públicas); e 125 em 2005 (50 na área de gestão social e ambiental; 35 na área de gestão pública e governança; e 40 na área de políticas públicas).

Nos artigos selecionados, foram avaliadas as seguintes categorias analíticas: número de autores por artigo, idioma do artigo, nacionalidade dos autores, instituição de origem dos autores, estado de origem dos autores, tipo de pesquisa, método de pesquisa, e estratégia de pesquisa.

Após a verificação das categorias analíticas nos 549 artigos selecionados no Enanpad, os dados foram tabulados e analisados com o apoio do programa Microsoft Excel ${ }^{\circledR}$. Tais dados estão dispostos em valores absolutos e percentuais, divididos em três períodos: 2000-2001, 2002-2003 e 2004-2005.

Algumas observações devem ser destacadas em relação aos procedimentos analíticos. A média de autores por artigo foi comparada entre: período, tipo de pesquisa e método empregado. Para tanto foi utilizado o Teste-T e o Teste Anova com Post Hoc de Tukey HSD para comparação entre as médias, por meio do software SPSS ${ }^{\circledR}$ 13.0. Para avaliar a proporção de artigos por tipo e método de pesquisa entre os períodos estudados, foi utilizado o Teste $\chi^{2}$ (Qui-quadrado), também com o uso do SPSS ${ }^{\circledR}$ 13.0. Para a contagem da instituição mais prolífica, levou-se em conta somente a filiação do primeiro autor dos artigos, pois essa não alterava significativamente os resultados e facilitava 
o trabalho de análise dos dados. Também em relação à avaliação do número de artigos por estado, foi considerado somente o primeiro autor.

A partir dos procedimentos metodológicos explicitados, são apresentados os resultados da análise da produção científica na área de administração pública e gestão social do Enanpad, no período de 2000 a 2005.

\section{Descrição e análise dos dados}

Na tabela 1, é apresentada a distribuição anual de artigos científicos publicados na área de administração pública e gestão social. Observa-se crescimento sucessivo no número de artigos no período de 2000 a 2004, com pequena redução no ano de 2005. O aumento maior no número de artigos foi do ano de 2002 (64 artigos) para 2003 (112 artigos), com um crescimento de aproximadamente $75 \%$, em grande parte devido ao incremento da área de gestão social e ambiental.

Como pode ser visto na tabela 1 , a área de administração pública do ano de 2000 foi substituída pelas áreas de gestão pública e governança e políticas públicas nos anos de 2001 e 2002. Já nos anos seguintes, 2003, 2004 e 2005, além das duas áreas anteriores, foi criada a área de gestão social e ambiental; as três estão inseridas dentro da grande área de administração pública e gestão social. No período analisado, a área de gestão pública e governança acumulou o maior número de artigos publicados, com total de 185 trabalhos.

Tabela 1

Artigos publicados na área de administração pública e gestão social de 2000 a 2005

\begin{tabular}{|c|c|c|c|c|c|c|c|}
\hline \multirow{2}{*}{ Área } & \multicolumn{6}{|c|}{ Período } & \multirow{2}{*}{$\begin{array}{l}\text { Total } \\
\text { área }\end{array}$} \\
\hline & 2000 & 2001 & 2002 & 2003 & 2004 & 2005 & \\
\hline Administração pública & 41 & - & - & - & - & - & 41 \\
\hline Gestão social e ambiental & - & - & - & 42 & 63 & 50 & 155 \\
\hline Gestão pública e governança & - & 35 & 38 & 32 & 45 & 35 & 185 \\
\hline Políticas públicas & - & 24 & 26 & 38 & 40 & 40 & 168 \\
\hline Total ano & 41 & 59 & 64 & 112 & 148 & 125 & 549 \\
\hline
\end{tabular}

Fonte: Dados primários da pesquisa.

Em virtude do crescente aumento de trabalhos publicados no Enanpad, houve a divisão da área de administração pública e gestão social em três su- 
báreas, o que possibilitou distribuir os artigos de acordo com seus temas específicos, direcionando melhor os trabalhos apresentados conforme o interesse de seus autores.

Como em outras áreas da administração, a administração pública e gestão social também apresentou crescimento significativo, acompanhando o desenvolvimento da disciplina como um todo. Com o crescente aumento no número de programas de pós-graduação no Brasil, era de se esperar que a área também sofresse tal influência, refletindo-se no aumento de publicações. Contudo o maior crescimento da área se deu em razão da ampliação do debate, que absorveu a área de gestão social e ambiental.

Dos artigos analisados, cerca de 95,63\% dos textos (525 artigos) foram publicados em português; $3,1 \%$ dos artigos foram publicados em inglês; e $1,27 \%$ foi apresentado em espanhol. De acordo com os dados, identifica-se que nos anos de 2003, 2004 e 2005 surgiu considerável número de trabalhos publicados em outros idiomas (inglês e espanhol), totalizando 19 artigos. Quanto aos autores, foi realizada uma divisão entre os que são de origem nacional e os estrangeiros: $97,8 \%$ dos autores são de nacionalidade brasileira; e 2,2\% de outros países, como Espanha e Argentina. Esse fato demonstra que, apesar de terem sido identificados cerca de 4,4\% de artigos publicados em outros idiomas, muitos deles pertencem a autores com nacionalidade brasileira que, possivelmente, têm algum contato com pesquisadores externos e/ou instituições estrangeiras.

No tocante ao número de autores por artigo, observou-se que cerca de $39,2 \%$ do total de artigos foram publicados por um autor; no período de 20002001 esse percentual atingiu o índice de 63\% do total de trabalhos (tabela 2). Na seqüência, encontram-se os artigos com dois autores, que representam $37,7 \%$ das publicações analisadas. Artigos com três autores representam 15,8\% do total. Somente no período de 2004-2005 não foi observado o predomínio de artigos publicados por apenas um autor, visto que nesse período ocorreu maior incidência de trabalhos com dois autores. No período de 2000-2001 não foram identificados artigos com mais de seis autores e nos anos subseqüentes foram apresentados somente quatro artigos com seis autores.

Como pode ser visto na tabela 2, o número médio de autores por artigo vem crescendo. Entretanto, de acordo com o teste Post Hoc de Tukey HSD, tal diferença é significativa somente entre os períodos de 2000-2001 e 2002-2003 (p-value $=0,003)$.

Comparando-se o número de autores que colaboram na produção de artigos na área de administração pública e gestão social com os dados encontrados em outras áreas da administração, pode-se observar que tal área tende 
a apresentar um maior número de autores que trabalham individualmente (Bertero, Vasconcelos e Binder, 2003; Fleury, 2003; Vieira, 2003). Tal fato pode ser visto como não muito positivo, pois a produção de artigos científicos em conjunto com outros pesquisadores da área de administração pode contribuir para a troca de experiência e aumento na qualidade dos trabalhos, uma vez que os autores podem apresentar conhecimentos e interesses de pesquisa complementares.

Tabela 2

Número de autores por artigo

\begin{tabular}{|lcrrrrrrr|}
\hline \multirow{2}{*}{$\begin{array}{l}\text { № de } \\
\text { autores }\end{array}$} & \multicolumn{9}{c}{ 2000-2001 } & \multicolumn{2}{c}{ 2002-2003 } & \multicolumn{2}{c}{ 2004-2005 } & \multicolumn{3}{c|}{ Total } \\
\cline { 2 - 6 } & \multicolumn{1}{c}{ № } & $\%$ & № & $\%$ & № & $\%$ & № & $\%$ \\
\hline 1 & 63 & 63 & 73 & 41,5 & 79 & 28,9 & 215 & 39,2 \\
2 & 25 & 25 & 66 & 37,5 & 116 & 42,5 & 207 & 37,7 \\
3 & 9 & 9 & 19 & 10,8 & 59 & 21,6 & 87 & 15,8 \\
4 & 2 & 2 & 12 & 6,8 & 14 & 5,1 & 28 & 5,1 \\
5 & 1 & 1 & 5 & 2,8 & 2 & 0,7 & 8 & 1,5 \\
6 & - & - & 1 & 0,6 & 3 & 1,1 & 4 & 0,7 \\
Total & 100 & & 176 & & 273 & & 549 & \\
Média & 1,53 & & 1,94 & & 2,06 & & 1,94 & \\
\hline
\end{tabular}

Fonte: Dados primários da pesquisa.

No geral, conforme se apresenta na tabela 2 , a média de autores por artigo foi de 1,94, permanecendo consideravelmente próxima nos três períodos, sendo menor $(1,53)$ no período de $2000-2001$ e maior $(2,06)$ no período de 2002-2003. Como em outras áreas da administração, em que a colaboração vem crescendo (Bertero, Vasconcelos e Binder, 2003; Vieira, 2003), a área de administração pública e gestão social vem apresentando tal crescimento, uma vez que no período de 2004-2005 se observa redução significativa no número de artigos publicados por um autor e ao mesmo tempo crescimento no número de artigos com dois e três autores. Com três autores o aumento foi superior a $100 \%$, passando de 19 para 59 artigos.

Espera-se que o aumento no número de autores por artigo seja mais representativo nos próximos anos, caso os grupos de pesquisa passem a atuar efetivamente, colocando em prática os propósitos pelos quais foram criados, 
que seria a criação e disseminação do conhecimento científico desenvolvido na academia (Bertero, Vasconcelos e Binder, 2003).

Quanto ao tipo de pesquisa, as publicações dividiram-se em 23,9\% de ensaios teóricos, nos quais foram conduzidas discussões e contraposições de diferentes abordagens teóricas ou simplesmente a revisão de referencial teórico relacionado a temas da área de administração pública e gestão social (tabela 3). Já os estudos de caráter teórico-empírico corresponderam a 76,1\% do total de artigos, mostrando que a área tende a desenvolver mais estudos de campo do que somente ensaios teóricos. Observa-se que a área apresentou maior número de artigos empíricos do que a maioria das outras áreas da administração (Bertero, Vasconcelos e Binder, 2003; Caldas, Tonelli e Lacombe, 2002; Hoppen, 1998; Hoppen e Meirelles, 2005; Fleury et al., 2003).

Diferentemente de outras áreas (Caldas, Tonelli e Lacombe, 2002; Tonelli et al., 2003), o número de artigos teórico-empíricos não vem crescendo na área de administração pública e gestão social (qui-quadrado $=2,666$, p-value $=0,264)$. Entretanto, o número de artigos que utilizam métodos quantitativos e multimétodos vem crescendo significantemente (qui-quadrado $=16,611$, p-value $=0,002$ ).

Tabela 3

Tipo e método de pesquisa

\begin{tabular}{|c|c|c|c|c|c|c|c|c|}
\hline \multirow{3}{*}{$\begin{array}{l}\text { Tipo de } \\
\text { pesquisa }\end{array}$} & \multicolumn{6}{|c|}{ Período } & \multirow{2}{*}{\multicolumn{2}{|c|}{ Total }} \\
\hline & \multicolumn{2}{|c|}{$2000-2001$} & \multicolumn{2}{|c|}{$2002-2003$} & \multicolumn{2}{|c|}{ 2004-2005 } & & \\
\hline & № & $\%$ & № & $\%$ & № & $\%$ & № & $\%$ \\
\hline Ensaio teórico & 30 & 30 & 38 & 21,6 & 63 & 23,1 & 131 & 23,9 \\
\hline Teórico-empírico & 70 & 70 & 138 & 78,4 & 210 & 76,9 & 418 & 76,1 \\
\hline Qualitativo & 58 & 82,9 & 95 & 68,8 & 126 & 60 & 279 & 66,7 \\
\hline Quantitativo & 5 & 7,1 & 34 & 24,6 & 61 & 29 & 100 & 23,9 \\
\hline Multimétodos & 7 & 10 & 9 & 6,5 & 23 & 11 & 39 & 9,3 \\
\hline Total & 100 & & 176 & & 273 & & 549 & \\
\hline
\end{tabular}

Fonte: Dados primários da pesquisa.

Vale ressaltar que o número médio de autores que colaboraram em ensaios teóricos (1,54 autores por artigo) é significantemente menor $(t=-5,374$, $p<0,001)$ que o número médio de autores por trabalho teórico-empírico $(2,06$ autores por artigo). Pesquisas de campo são mais trabalhosas do que ensaios teóricos, o que leva os pesquisadores a buscarem maior colaboração. 
Além disso, como levantado pelo teste Post Hoc de Tukey HSD, quando se trata de artigos que utilizam métodos quantitativos ou multimétodos, o número de autores por artigo é significantemente maior do que aqueles que utilizam métodos qualitativos de pesquisa: média de 2,35 autores em estudos multimétodos (p-value $=0,05$ ) e de 2,26 autores em estudos quantitativos ( $\mathrm{p}$-value $=0,027$ ) contra média de 1,95 autor em estudos qualitativos. Porém, se for comparada a média de autores entre artigos quantitativos e multimétodos, não há diferença significativa ( $\mathrm{p}$-value $=0,860$ ).

Ainda que haja concentração de pesquisas de caráter teórico-empírico, que buscam entender a realidade das organizações na área, observou-se a predominância de estudos qualitativos (66,7\%), conforme tabela 3 , nos quais não são utilizadas técnicas e instrumentos de análise e coleta de dados apoiados estatisticamente, muitas vezes por serem analisadas poucas ou somente uma organização.

No período de 2000-2001, os trabalhos de natureza qualitativa dominaram $82,9 \%$ do total de artigos publicados no evento. De acordo com Bertero, Vasconcelos e Binder (2003) e Hoppen e Meirelles (2005), a ampla utilização de métodos qualitativos expressa a fragilidade e a imaturidade do campo de pesquisa em administração, não diferindo na área de administração pública e gestão social. Muitos dos estudos realizados na área de administração pública e gestão social provavelmente ficam somente na fase exploratória, não evoluindo para a construção de estudos de natureza explicativa, o que provoca, conseqüentemente, a descontinuidade dos temas que são desenvolvidos nos estudos da área. Contudo, como em outras áreas da administração, o número de artigos teórico-empíricos que utilizam métodos quantitativos e multimétodos vem crescendo significativamente no período analisado, demonstrando, pelo menos aparentemente, que a área está amadurecendo.

Conforme a tabela 4, na área de administração pública e gestão social, entre as diferentes estratégias qualitativas de pesquisa utilizadas, verificou-se a primazia dos estudos de caso (55,7\% dos artigos analisados), seguido da estratégia de pesquisa documental em $29,2 \%$ dos artigos.

No período de 2000-2001, a incidência de pesquisas que utilizaram a estratégia de estudo de caso atingiu o índice de $63,1 \%$ do total dos estudos qualitativos e a pesquisa documental $36,9 \%$, não sendo identificados artigos com outras modalidades de estratégias de pesquisa. Apesar de uma redução nesses índices nos anos posteriores, observa-se que há interesse de pesquisadores na área de administração pública e gestão social pelo desenvolvimento de pesquisas tendo como objeto de estudo organizações isoladas. Esse resultado se assemelha ao observado no estudo de Hoppen e co-autores (1998), onde 
foi identificada a predominância da estratégia de estudo de caso nas pesquisas desenvolvidas na área de sistema de informação.

Destaca-se o alto percentual de utilização de pesquisa documental em decorrência da disponibilidade de material de qualidade, que se torna elemento de análise em várias pesquisas científicas relacionadas ao tema de administração pública e gestão social. Todavia, apesar do número de artigos que utilizam pesquisa documental vir crescendo, percentualmente ele vem caindo em decorrência da entrada da área de gestão social e ambiental, cujos artigos raramente utilizam tal método, no âmbito da administração pública.

Tabela 4

Estratégias qualitativas de pesquisa

\begin{tabular}{|c|c|c|c|c|c|c|c|c|}
\hline \multirow{3}{*}{ Estratégia } & \multicolumn{6}{|c|}{ Período } & \multirow{2}{*}{\multicolumn{2}{|c|}{ Total }} \\
\hline & \multicolumn{2}{|c|}{$2000-2001$} & \multicolumn{2}{|c|}{$2002-2003$} & \multicolumn{2}{|c|}{ 2004-2005 } & & \\
\hline & № & $\%$ & № & $\%$ & № & $\%$ & № & $\%$ \\
\hline Estudo de caso & 41 & 63,1 & 61 & 58,7 & 75 & 50,3 & 177 & 55,7 \\
\hline Pesquisa documental & 24 & 36,9 & 31 & 29,8 & 38 & 25,5 & 93 & 29,2 \\
\hline Observação participante & - & - & - & - & 1 & 0,7 & 1 & 0,3 \\
\hline Pesquisa-ação & - & - & 1 & 1 & 3 & 2 & 4 & 1,3 \\
\hline Pesquisa de campo & - & - & 9 & 8,7 & 18 & 12,1 & 27 & 8,5 \\
\hline Análise de conteúdo & - & - & - & - & 8 & 5,4 & 8 & 2,5 \\
\hline Focus group & - & - & 2 & 1,9 & 1 & 0,7 & 3 & 0,9 \\
\hline Outras & - & - & - & - & 5 & 3,4 & 5 & 1,6 \\
\hline Total & 65 & & 104 & & 149 & & 318 & \\
\hline
\end{tabular}

Fonte: Dados primários da pesquisa.

Bertero, Vasconcelos e Binder (2003:57) salientam que "os estudos de caso a rigor são freqüentemente 'exemplos', não atendendo às exigências do protocolo habitual para estudos de caso enquanto pesquisa academicamente válida". Em geral, os estudos de caso são caracterizados como cases utilizados como veículo de divulgação e promoção de empresas ou como suporte técnico para consultorias desenvolvidas na área.

Entre as estratégias quantitativas de pesquisa que compõem $23,9 \%$ dos estudos teórico-empírico, conforme tabela 3, destacam-se as surveys como mais utilizadas pelos pesquisadores da área de administração pública e gestão social, representando 48,9\% dos estudos quantitativos, de acordo com a 
tabela 5. Em segundo lugar, encontra-se a estratégia de séries temporais e painel que foi utilizada por aproximadamente $24,5 \%$ das pesquisas de natureza quantitativa entre as publicações científicas analisadas. Nesse tipo de pesquisa, os autores buscam analisar os resultados de determinados programas governamentais por meio de dados econômicos ou financeiros, disponibilizados em documentos (eletrônicos ou não).

Tabela 5

Estratégias quantitativas de pesquisa

\begin{tabular}{|c|c|c|c|c|c|c|c|c|}
\hline \multirow{3}{*}{ Estratégia } & \multicolumn{6}{|c|}{ Período } & \multirow{2}{*}{\multicolumn{2}{|c|}{ Total }} \\
\hline & \multicolumn{2}{|c|}{$2000-2001$} & \multicolumn{2}{|c|}{$2002-2003$} & \multicolumn{2}{|c|}{ 2004-2005 } & & \\
\hline & № & $\%$ & № & $\%$ & № & $\%$ & № & $\%$ \\
\hline Survey & 6 & 50 & 24 & 55,8 & 38 & 45,2 & 68 & 48,9 \\
\hline Experimento & - & - & - & - & 2 & 2,4 & 2 & 1,4 \\
\hline Séries temporais e painel & 2 & 16,7 & 9 & 20,9 & 23 & 27,4 & 34 & 24,5 \\
\hline Modelagem & 4 & 33,3 & 7 & 16,3 & 6 & 7,1 & 25 & 18 \\
\hline Análise estatística & - & - & 2 & 4,7 & 14 & 16,7 & 8 & 5,8 \\
\hline Outros & - & - & 1 & 2,3 & 1 & 1,2 & 2 & 1,4 \\
\hline Total geral & 12 & & 43 & & 84 & & 139 & \\
\hline
\end{tabular}

Fonte: Dados primários da pesquisa.

Esse resultado se aproxima ao apresentado por Froemming e co-autores (2000b), quando elaboraram um inventário das características metodológicas básicas da produção científica da área de marketing no Brasil na década de 1990, apontando que, entre os estudos de natureza quantitativa, houve a predominância das pesquisas utilizando surveys.

Posteriormente à análise das estratégias de pesquisa, foi verificado o número de artigos por instituição, com base nas instituições em que os autores estavam filiados na época da publicação do artigo.

Na tabela 6, ressalta-se que, no geral, a publicação científica na área de administração pública e gestão social é dominada por três instituições de ensino superior, sendo duas privadas e uma pública. As instituições privadas são a FGV em São Paulo, correspondendo a 13,7\% do número de artigos publicados, e a FGV no Rio de Janeiro, com 13,5\% da publicação científica da área. A instituição pública é a UFBA (Universidade Federal da Bahia), que representa $11,5 \%$ dos artigos publicados. Juntas as três instituições foram responsáveis por $38,6 \%$ dos artigos publicados no Enanpad no período analisado. 
A concentração da publicação científica na área de administração pública e gestão social em três instituições (FGV em São Paulo, FGV no Rio de Janeiro e UFBA) pode ser explicada pela existência, nessas instituições, de cursos de pós-graduação stricto sensu em nível de mestrado e doutorado, com linhas de pesquisas específicas em administração pública, possuindo maior número de pesquisadores interessados nos temas da área.

Rossoni, Ferreira Júnior e Hocayen-da-Silva (2006), ao analisarem a produção científica na área de administração de ciência e tecnologia, identificaram que cerca de $36 \%$ da produção científica na área, no período entre 2000 e 2005, foi dominada por cinco instituições, sendo todas caracteristicamente de ensino superior de domínio público (estadual ou federal); a primeira instituição de natureza privada ocupou apenas a sexta colocação. Por sua vez, na área de administração pública e gestão social observa-se (tabela 6) maior concentração da publicação científica entre as instituições identificadas na pesquisa do que na área de ciência em tecnologia.

Tabela 6

Número de artigos por instituição

\begin{tabular}{|c|c|c|c|c|c|c|}
\hline \multirow{2}{*}{ Instituição } & \multicolumn{3}{|c|}{ Período } & \multirow{2}{*}{ Total } & \multirow{2}{*}{$\%$} & \multirow{2}{*}{$\%$ Acum. } \\
\hline & $2000-2001$ & $2002-2003$ & 2004-2005 & & & \\
\hline Total & 100 & 176 & 273 & 549 & 100 & \\
\hline FGV (São Paulo) & 12 & 21 & 42 & 75 & 13,7 & 13,7 \\
\hline FGV (Rio) & 21 & 21 & 32 & 74 & 13,5 & 27,1 \\
\hline UFBA & 19 & 25 & 19 & 63 & 11,5 & 38,6 \\
\hline UFRGS & 7 & 6 & 15 & 28 & 5,1 & 43,7 \\
\hline UnB & 8 & 8 & 12 & 28 & 5,1 & 48,8 \\
\hline USP & 3 & 9 & 12 & 24 & 4,4 & 53,2 \\
\hline FJP & - & 12 & 8 & 20 & 3,6 & 56,8 \\
\hline UFMG & 4 & 5 & 9 & 18 & 3,3 & 60,1 \\
\hline UFPE & 3 & 6 & 6 & 15 & 2,7 & 62,8 \\
\hline UFSC & - & 5 & 9 & 14 & 2,6 & 65,4 \\
\hline PUC-MG & 1 & 5 & 4 & 10 & 1,8 & 67,2 \\
\hline UEL & - & 7 & 3 & 10 & 1,8 & 69,0 \\
\hline UFRN & 3 & 3 & 3 & 9 & 1,6 & 70,7 \\
\hline PUC-SP & 2 & 3 & 3 & 8 & 1,5 & 72,1 \\
\hline
\end{tabular}




\begin{tabular}{|c|c|c|c|c|c|c|}
\hline \multirow{2}{*}{ Instituição } & \multicolumn{3}{|c|}{ Período } & \multirow{2}{*}{ Total } & \multirow{2}{*}{$\%$} & \multirow{2}{*}{$\%$ Acum } \\
\hline & $2000-2001$ & $2002-2003$ & 2004-2005 & & & \\
\hline Mackenzie & - & 2 & 5 & 7 & 1,3 & 73,4 \\
\hline PUC-Rio & 1 & 2 & 4 & 7 & 1,3 & 74,7 \\
\hline Ufla & - & 1 & 6 & 7 & 1,3 & 76,0 \\
\hline UFPR & 4 & - & 3 & 7 & 1,3 & 77,2 \\
\hline Unifor & - & - & 7 & 7 & 1,3 & 78,5 \\
\hline Univali & - & 2 & 5 & 7 & 1,3 & 79,8 \\
\hline UFC & - & 2 & 4 & 6 & 1,1 & 80,9 \\
\hline PUC-PR & - & 2 & 3 & 5 & 0,9 & 81,8 \\
\hline Unifacs & - & 4 & 1 & 5 & 0,9 & 82,7 \\
\hline Unisinos & - & - & 4 & 4 & 0,7 & 83,4 \\
\hline Imes & - & 2 & 1 & 3 & 0,5 & 84 \\
\hline UFF & 1 & 2 & - & 3 & 0,5 & 84,5 \\
\hline UFRJ & - & 1 & 2 & 3 & 0,5 & 85,1 \\
\hline Uninove & - & - & 3 & 3 & 0,5 & 85,6 \\
\hline Unisantos & - & - & 3 & 3 & 0,5 & 86,2 \\
\hline USM & - & - & 3 & 3 & 0,5 & 86,7 \\
\hline Fiocruz & - & 2 & - & 2 & 0,4 & 87,1 \\
\hline Ibmec-RJ & - & - & 2 & 2 & 0,4 & 87,4 \\
\hline lesb & - & - & 2 & 2 & 0,4 & 87,8 \\
\hline Uece & 1 & - & 1 & 2 & 0,4 & 88,2 \\
\hline Ufes & 2 & - & - & 2 & 0,4 & 88,5 \\
\hline UFS & - & 1 & 1 & 2 & 0,4 & 88,9 \\
\hline UFSM & 1 & - & 1 & 2 & 0,4 & 89,3 \\
\hline UFV & 1 & - & 1 & 2 & 0,4 & 89,6 \\
\hline Unicamp & 1 & 1 & - & 2 & 0,4 & 90 \\
\hline Unicenp & - & - & 2 & 2 & 0,4 & 90,3 \\
\hline Unitau & - & - & 2 & 2 & 0,4 & 90,7 \\
\hline URB & - & 1 & 1 & 2 & 0,4 & 91,1 \\
\hline Outras & 5 & 15 & 29 & 49 & 8,9 & 100 \\
\hline
\end{tabular}

Fonte: Dados primários da pesquisa. 
Levando-se em consideração as 10 instituições mais prolíficas, temos $65,4 \%$ dos artigos da área produzidos por elas, o que reforça o argumento de que a produção na área é centralizada e estratificada. Como já ressaltado por Bertero, Caldas e Wood Jr. (1998), o conhecimento científico é estratificado, apresentando centro e periferia, no qual algumas poucas instituições representam a maioria da produção científica. No caso da área de administração pública e gestão social, a partir da décima instituição listada, verifica-se que a publicação científica é bastante pulverizada, justificando a estratificação comentada pelos autores.

Na tabela 6, encontram-se também diversas outras instituições de ensino superior e alguns institutos de pesquisa, que possivelmente incentivam a publicação científica entre seus profissionais e pesquisadores. Tais instituições estão distribuídas em diferentes estados do país, como apresentado.

O número de artigos por unidade federativa foi identificado a partir das regiões em que se localizavam as instituições nas quais os autores dos trabalhos estavam filiados: para cada autor foi definida uma instituição e seu respectivo estado (tabela 7).

Observa-se, na tabela 7, que as publicações científicas da área de administração pública e gestão social estão concentradas na região Sudeste do país (São Paulo e Rio de Janeiro), que juntas dominam 42,6\% dos artigos publicados nos anais do Enanpad entre os anos de 2000 e 2005. O estado de São Paulo foi responsável por aproximadamente $25,5 \%$ das publicações analisadas, provavelmente em virtude de possuir o maior número de instituições a que estavam filiados os pesquisadores autores dos trabalhos.

Resultado interessante que deve ser destacado é: o número de artigos oriundos de pesquisadores e/ou instituições do exterior (10 estudos, representando $1,8 \%$ do total) conforme tabela 7 , foi superior ao número de artigos publicados em muitos estados brasileiros. Tal constatação parece demonstrar uma baixa tendência de publicação científica de pesquisadores pertencentes a instituições de certos estados.

A concentração da publicação científica na área de administração pública e gestão social é evidente (tabela 7), quando se observa que, de 19 unidades federativas identificadas no artigo, além dos trabalhos de origem estrangeira, as nove primeiras (São Paulo, Rio de Janeiro, Bahia, Minas Gerais, Rio Grande do Sul, Distrito Federal, Paraná, Santa Catarina e Ceará) dominaram conjuntamente $91,8 \%$ do total de artigos científicos publicados no período de 2000 a 2005. 
Tabela 7

Número de artigos por unidade federativa

\begin{tabular}{|c|c|c|c|c|c|c|}
\hline \multirow{2}{*}{ Instituição } & \multicolumn{3}{|c|}{ Período } & \multirow{2}{*}{ Total } & \multirow{2}{*}{$\%$} & \multirow{2}{*}{$\%$ Acum. } \\
\hline & $2000-2001$ & $2002-2003$ & 2004-2005 & & & \\
\hline Total & 100 & 176 & 273 & 549 & 100 & \\
\hline SP & 20 & 43 & 77 & 140 & 25,5 & 25,5 \\
\hline RJ & 23 & 29 & 42 & 94 & 17,1 & 42,6 \\
\hline BA & 19 & 31 & 23 & 73 & 13,3 & 55,9 \\
\hline MG & 6 & 23 & 32 & 61 & 11,1 & 67 \\
\hline RS & 8 & 7 & 23 & 38 & 6,9 & 74 \\
\hline DF & 9 & 8 & 14 & 31 & 5,6 & 79,6 \\
\hline PR & 4 & 9 & 14 & 27 & 4,9 & 84,5 \\
\hline SC & - & 8 & 17 & 25 & 4,6 & 89,1 \\
\hline CE & 1 & 2 & 12 & 15 & 2,7 & 91,8 \\
\hline PE & 3 & 6 & 6 & 15 & 2,7 & 94,5 \\
\hline EXT. & 1 & 4 & 5 & 10 & 1,8 & 96,4 \\
\hline RN & 3 & 4 & 3 & 10 & 1,8 & 98,2 \\
\hline SE & 1 & 1 & 1 & 3 & 0,5 & 98,7 \\
\hline ES & 2 & - & - & 2 & 0,4 & 99,1 \\
\hline GO & - & - & 1 & 1 & 0,2 & 99,3 \\
\hline MS & - & 1 & - & 1 & 0,2 & 99,5 \\
\hline MT & - & - & 1 & 1 & 0,2 & 99,6 \\
\hline PB & - & - & 1 & 1 & 0,2 & 99,8 \\
\hline TO & - & - & 1 & 1 & 0,2 & 100 \\
\hline
\end{tabular}

Fonte: Dados primários da pesquisa.

\section{Considerações finais}

Este artigo apresenta um quadro geral da produção científica no campo de administração pública e gestão social, por meio de dados levantados a partir dos artigos publicados nos anais do Enanpad, de 2000 a 2005.

Verificou-se crescimento constante no número de artigos publicados na área de administração pública e gestão social de 2000 a 2004; porém, no ano de 2005, identifica-se uma queda no número de publicações. A subárea com maior número de trabalhos foi a de gestão pública e governança, com 185 artigos publicados.

No que se refere ao número de autores por artigo, a média encontrada foi de 1,94 autor; essa média cresce gradativamente no período analisado. 
Contudo artigos com dois ou três autores atingiram índices significantes na análise. Tal constatação parece indicar que são reduzidas as publicações decorrentes de trabalhos de grupos de pesquisa, mas sim de resultados de interações baseadas em relacionamentos ou interesses de pesquisa pessoais.

A grande maioria dos artigos foi classificada como do tipo teórico-empírico. Esse resultado parece confirmar uma característica particular da área de administração pública e gestão social, que é a de realizar trabalhos a partir de dados empíricos, como a avaliação de programas do governo, com base em seus resultados econômicos, financeiros e sociais. Nos artigos teórico-empíricos, o método de pesquisa predominante foi o qualitativo, ainda que o quantitativo tenha sido bastante empregado nos trabalhos analisados. Cabe destacar que, durante o período considerado para a análise, a proporção entre trabalhos qualitativos e quantitativos oscilou consideravelmente: os trabalhos de cunho qualitativo que, no primeiro período, dominavam as publicações, vêm perdendo espaço para os estudos de natureza quantitativa, com elevado crescimento no período.

Nos trabalhos qualitativos, as estratégias de pesquisa mais utilizadas foram a do estudo de caso, verificada em $55,7 \%$ dos artigos, e a de pesquisa documental, que consta em $29,2 \%$ das publicações. A maior utilização do estudo de caso evidencia uma fragilidade nas publicações científicas da área de administração pública e gestão social, fato encontrado ainda em outras áreas da administração, tais como estratégia, estudos organizacionais, sistema de informação e administração de ciência e tecnologia.

Em relação às estratégias quantitativas de pesquisa, a survey foi a mais utilizada. Contudo cabe destacar o número razoável de artigos que fizeram uso de séries temporais e painel. Estudos futuros podem verificar a qualidade de tais publicações, avaliando quantas são de natureza exploratória, descritiva e/ou causal. Deve-se ressaltar que o uso de tal método vem crescendo significativamente na área, bem como o uso de multimétodos.

Analisado o número de artigos por instituição, verificou-se que apenas cinco instituições foram responsáveis por aproximadamente $50 \%$ das publicações no período analisado. As instituições mais prolíficas se encontram concentradas na região Sudeste do país (São Paulo e Rio de Janeiro). Ligado a essa categoria está o número de artigos por unidade federativa, em que, além de apontar os estados de São Paulo, Rio de Janeiro, Bahia, Minas Gerais e Rio Grande do Sul, além de Brasília, como unidades federativas mais prolíficas, destaca-se o baixo número de artigos publicados por instituições de determinados estados, notadamente das regiões Norte e Centro-Oeste. Tal constatação fica ainda mais evidenciada em virtude do número de artigos do exterior 
ter sido maior do que os publicados em instituições de alguns estados dessas regiões.

Os resultados referentes à região Sudeste podem ser por que nessa região estão localizadas duas das principais instituições especializadas no ensino de administração pública, em nível de graduação e pós-graduação (mestrado e doutorado).

Como limitação de pesquisa, destaca-se que esta focou somente o período de 2000 a 2005. Poderia ter sido avaliado um período maior de tempo, para representar a situação da produção científica em administração pública e gestão social mais próxima de sua realidade. Além disso, outros eventos, com menor classificação no sistema Qualis, também poderiam ter sido avaliados, bem como artigos publicados em periódicos específicos da área.

Para pesquisas futuras, sugere-se que sejam avaliados, além dos critérios quantitativos aqui expostos, os critérios de qualidade dos artigos de natureza tanto quantitativa quanto qualitativa. Além disso, outra possível contribuição, que poderia ser obtida com futuros estudos, seria a avaliação da rede de relações, tanto entre os pesquisadores quanto entre as instituições, fomentando novas conclusões sobre a natureza da colaboração entre pesquisadores, no campo de administração pública e gestão social e nas demais áreas de pesquisa da administração.

\section{Referências bibliográficas}

BERTERO, C. O.; CALDAS, M. P.; WOOD JR., T. Produção científica em administração de empresas: provocações, insinuações e contribuições para um debate local. Revista de Administração Contemporânea, Curitiba, v. 3, n. 1, p. 147-178, jan./abr. 1999.

vocações insinuações . Produção científica em administração de empresas. proASSOCIAÇÃO NACIONAL DE PROGRAMAS DE PÓS-GRADUAÇÃO EM ADMINISTRAÇÃO, 27.,1998, Foz do Iguaçu. Anais... Foz do Iguaçu: Anpad, 1998.

; KEINERT, T. M. M. A evolução da análise organizacional no Brasil (1961-93).

Revista de Administração de Empresas, São Paulo, v. 34, n. 3, p. 81-90, maio/jun. 1994.

; VASCONCELOS, F. C.; BINDER, M. P. Estratégia empresarial: a produção científica brasileira entre 1991 e 2002. Revista de Administração de Empresas, São Paulo, v. 43, n. 4, p. 48-63, out./dez. 2003. 
BIGNETTI, L. P; PAIVA, E. L. Ora (direis) ouvir estrelas: estudo das citações de autores de estratégia na produção acadêmica brasileira. Revista de Administração Contemporânea, Curitiba, v. 6, n. 1, p. 105-125, jan./abr. 2002.

. Estudo das citações de autores de estratégia na produção acadêmi-

ca brasileira. In: ENCONTRO DA ASSOCIAÇÃO NACIONAL DE PROGRAMAS DE PÓS-GRADUAÇÃO EM ADMINISTRAÇÃO, 25., 2001, Campinas. Anais... Campinas: Anpad, 2001.

CALDAS, M. P.; TINOCO, T.; CHU, R. A. Análise bibliométrica dos artigos de RH publicados no Enanpad na década de 1990 - um mapeamento a partir das citações dos heróis, endogenias e jactâncias que fizeram a história da produção científica da área. In: ENCONTRO DA ASSOCIAÇÃO NACIONAL DE PROGRAMAS DE PÓSGRADUAÇÃ̃O EM ADMINISTRAÇÃO, 27., 2003, Atibaia. Anais... Atibaia: Anpad, 2003.

; TONELLI, M. J.; LACOMBE, B. M. B. Espelho, espelho meu: meta-estudo da produção científica em recursos humanos nos Enanpads da década de 90. In: ENCONTRO DA ASSOCIAÇÃO NACIONAL DE PROGRAMAS DE PÓS-GRADUAÇÃO EM ADMINISTRAÇÃO, 26., 2002, Salvador. Anais... Salvador: Anpad, 2002.

CAMARGOS, M. A.; COUTINHO, E. S.; AMARAL, H. F. O perfil da área de finanças do Enanpad: um levantamento da produção científica e de suas tendências entre 2000-2004. In: ENCONTRO DA ASSOCIAÇÃO NACIONAL DE PROGRAMAS DE PÓS-GRADUAÇÃO EM ADMINISTRAÇÃO, 29., 2005, Brasília. Anais... Brasília: Anpad, 2005.

CARDOSO, R. L.; MENDONÇA NETO, O. R.; SAKATA, M. C. G. Pesquisa científica em contabilidade entre 1990 e 2003. Revista de Administração de Empresas, São Paulo, v. 45, n. 2, p. 34-45, abr./jun. 2005.

CASTRO, C. M. A prática da pesquisa. São Paulo: McGraw-Hill, 1978.

FLEURY, S. et al. Análise do perfil dos artigos publicados na Revista de Administração Pública — RAP — no período 1992-2002. Rio de Janeiro: Eaesp/FGV, 2003.

FROEMMING, L. M. S. et al. Inventário de artigos científicos na área de marketing no Brasil. Revista de Administração Contemporânea, Curitiba, v. 4, n. 2, p. 159-173, maio/ago. 2000a.

et al. Análise da qualidade dos artigos científicos da área de marketing do Brasil: as pesquisas Survey na década de 90. Revista de Administração Contemporânea, Curitiba, v. 4, n. 3, p. 201-219, set./dez. 2000b.

GODOY, A. S. Introdução à pesquisa qualitativa e suas possibilidades: uma revisão histórica dos principais autores e obras que refletem esta metodologia de pesquisa 
em ciências sociais. Revista de Administração de Empresas, São Paulo, v. 35, n. 2, p. 57-63, mar./abr. 1995.

HOPPEN, N. Sistemas de Informação no Brasil: uma análise dos artigos científicos dos anos 90. Revista de Administração Contemporânea, Curitiba, v. 2, n. 3, p. 151177, set./dez. 1998.

et al. Sistemas de informação no Brasil: uma análise dos artigos científicos dos anos 90. In: ENCONTRO DA ASSOCIAÇÃO NACIONAL DE PROGRAMAS DE PÓS-GRADUAÇÃO EM ADMINISTRAÇÃO, 22., 1998, Foz do Iguaçu. Anais... Foz do Iguaçu: Anpad, 1998.

; MEIRELLES, F. S. Sistemas de informação: um panorama da pesquisa científica entre 1990 e 2003. Revista de Administração de Empresas, São Paulo, v. 45, n. 1, p. 24-35, jan./mar. 2005.

KEINERT, T. M. M. O que é administração pública no Brasil? In: ENCONTRO DA ASSOCIAÇÃO NACIONAL DE PROGRAMAS DE PÓS-GRADUAÇÃO EM ADMINISTRAÇÃO, 24., 2000, Florianópolis. Anais... Florianópolis: Anpad, 2000.

LEAL, R. P. C.; OLIVEIRA, J.; SOLURI, A. F. Perfil da pesquisa em finanças no Brasil. Revista de Administração de Empresas, São Paulo, v. 43, n. 1, p. 91-104, jan./mar. 2003.

MAC-ALLISTER, M. Fazer ciência no campo dos estudos organizacionais In: ENCONTRO DE ESTUDOS ORGANIZACIONAIS, 2., 2002, Recife. Anais... Recife: Anpad, 2002.

MACHADO-DA-SILVA, C. L.; CUNHA, V. C.; AMBONI, N. Organizações: o estado da arte da produção acadêmica no Brasil. In: ENCONTRO DA ASSOCIAÇÃO NACIONAL DE PROGRAMAS DE PÓS-GRADUAÇÃO EM ADMINISTRAÇÃO, 14., 1990, Belo Horizonte. Anais... Belo Horizonte: Anpad, 1990.

MARCONI, M. A.; LAKATOS, E. M. Técnicas de pesquisa: planejamento e execução de pesquisas, amostragens e técnicas de pesquisa, elaboração e interpretação de dados. São Paulo: Atlas, 1990.

MARIZ, L. A. et al. O reinado dos estudos de caso em teoria das organizações: imprecisões e alternativas. In: ENCONTRO DE ESTUDOS ORGANIZACIONAIS, 3., 2004, Atibaia. Anais... Atibaia: Anpad, 2004.

MENDONÇA NETO, O. R. et al. Estudo sobre as publicações científicas em contabilidade: uma análise de 1990 até 2003. In: ENCONTRO DA ASSOCIAÇÃO NACIONAL DE PROGRAMAS DE PÓS-GRADUAÇÃO EM ADMINISTRAÇÃO, 28., 2004, Curitiba. Anais... Curitiba: Anpad, 2004. 
MOREIRA, S. V. Análise documental como método e como técnica. In: DUARTE, J.; BARROS, A. (Orgs.). Métodos e técnicas de pesquisa em comunicação. São Paulo: Atlas, 2005. cap. 17, p. 269-279.

NEUMAN, L. W. Social research methods: qualitative and quantitative approaches. Boston: Allyn \& Bacon, 1997.

PACHECO, R. S. Administração pública nas revistas especializadas - Brasil, 1995-2002. Revista de Administração de Empresas, São Paulo, v. 43, n. 4, p. 63-71, out./dez. 2003.

PEGINO, P. M. F. As bases filosóficas das publicações na área de estratégia das organizações nos encontros nacionais da Anpad. In: ENCONTRO DA ASSOCIAÇÃO NACIONAL DE PROGRAMAS DE PÓS-GRADUAÇÃO EM ADMINISTRAÇÃO, 29., 2005, Brasília. Anais... Brasília: Anpad, 2005.

PERIN, M. G. et al. A pesquisa Survey em artigos de marketing nos Enanpads da década de 90. In: ENCONTRO DA ASSOCIAÇÃO NACIONAL DE PROGRAMAS DE PÓS-GRADUAÇÃO EM ADMINISTRAÇÃO, 24., 2000, Florianópolis. Anais... Florianópolis: Anpad, 2000.

RODRIGUES, S. B.; CARRIERI, A. P. A tradição anglo-saxônica nos estudos organizacionais brasileiros. Revista de Administração Contemporânea, Curitiba, p. 81-102, 2001. edição especial.

ROSSONI, L.; FERREIRA JÚNIOR, I.; HOCAYEN-DA-SILVA, A. J. Administração de ciência e tecnologia: a produção científica brasileira entre 2000 e 2005. In: SIMPÓSIO DE GESTÃO DA INOVAÇÃO TECNOLÓGICA, 24., 2006, Gramado. Anais...Gramado: Anpad, 2006.

TONELLI, M. J. et al. Produção acadêmica em recursos humanos no Brasil: 19912000. Revista de Administração de Empresas, São Paulo, v. 43, n. 1, p. 105-122, jan./mar. 2003.

VERGARA, S. C.; CARVALHO JR., D. S. Nacionalidade dos autores referenciados na literatura brasileira sobre organizações. In: ENCONTRO DA ASSOCIAÇÃO NACIONAL DE PROGRAMAS DE PÓS-GRADUAÇÃO EM ADMINISTRAÇÃO, 19., 1995, João Pessoa. Anais... João Pessoa: Anpad, 1995.

; PINTO, M. C. S. Nacionalidade das referências teóricas em análise organizacional: um estudo das nacionalidades dos autores referenciados na literatura brasileira. In: ENCONTRO DE ESTUDOS ORGANIZACIONAIS, 1., 2000, Curitiba. Anais... Curitiba: Anpad, 2000.

. Referências teóricas em análise organizacional: um estudo das nacionalidades dos autores referenciados na literatura brasileira. Revista de Administração Contemporânea, Curitiba, p. 103-121, 2001. edição especial. 
VIEIRA, F. G. D. Ações empresariais e prioridades de pesquisa em marketing: tendências no Brasil e no mundo segundo a percepção dos acadêmicos brasileiros. In: ENCONTRO DA ASSOCIAÇÃO NACIONAL DE PROGRAMAS DE PÓS-GRADUAÇÃO EM ADMINISTRAÇÃO, 23., 1999, Foz do Iguaçu. Anais... Foz do Iguaçu: Anpad, 1999.

. Narciso sem espelho: a publicação brasileira de marketing. Revista de Administração de Empresas, São Paulo, v. 43, n. 1, p. 81-90, jan./mar. 2003.

. Panorama acadêmico científico e temáticas de estudos de marketing no Brasil. In: ENCONTRO DA ASSOCIAÇÃO NACIONAL DE PROGRAMAS DE PÓSGRADUAÇÃO EM ADMINISTRAÇÃO, 24., 2000, Florianópolis. Anais... Florianópolis: Anpad, 2000.

. Por quem os sinos dobram? uma análise da publicação científica na área de marketing do Enanpad. In: ENCONTRO DA ASSOCIAÇÃO NACIONAL DE PROGRAMAS DE PÓS-GRADUAÇÃO EM ADMINISTRAÇÃO, 22., 1998, Foz do Iguaçu. Anais... Foz do Iguaçu: Anpad, 1998.

WOOD JR., T.; PAULA, A. P. P. Top-management: pesquisa sobre as revistas populares de gestão no Brasil. In: ENCONTRO DA ASSOCIAÇÃO NACIONAL DE PROGRAMAS DE PÓS-GRADUAÇÃO EM ADMINISTRAÇÃO, 26., 2002, Salvador. Anais... Salvador: Anpad, 2002. 